\title{
Atlas of Invisible Spaces: mapping in school environments
}

\author{
Antje Lehn Dipl.-Ing \\ Senior Scientist, Academy of Fine Arts, Institute for Art and Architecture, \\ Vienna, Austria (a.lehn@akbild.ac.at)
}

Contemporary city planning frequently involves participation processes which are based on the ability to communicate about architectural and urban cultures. This raises the issue of whether and how all members of a diverse society can be empowered to address matters concerning urban quality and atmospheric values. Consciousness of a place develops intensively in adolescence, a period in which young people spend an increasing amount of time at school. Therefore, the influence of the school surroundings on the urban knowledge of young citizens is essential. This paper discusses the question which spatial image young adults produce of their school environment and how this knowledge can be improved through architectural education. The goal of this research project is to develop a set of transferable mapping strategies, which allow to collect urban knowledge and to communicate urban qualities among heterogeneous groups in educational settings. A case study set in Vienna focuses on a school with diverse student groups to test non-normative mapping methods for the visualisation of city images. These maps combine mind maps, artistic representation and narratives to challenge the relation of pupil, school and the city and to make everyday spatial knowledge visible and valuable.

\begin{abstract}
This city can be known only by an activity of an ethnographic kind: you must orient yourself in it not by book, by address, but by walking, by sight, by habit, by experience; here every discovery is intense and fragile, it can be repeated or recovered only by memory of the trace it has left in you: to visit a place for the first time is thereby to begin to write it: the address not being written, it must establish its own writing.

(Barthes, 1982: p. 36)
\end{abstract}

\section{Introduction}

Today city space is understood as a construction process permanently redefined by the users rather than as a static construction; therefore, city planners need to understand and address the city users if they want to intervene in this process. In the final section of his book The Image of the City, Kevin Lynch (1960: p. 158) points out the importance of investigating the city images of different societal groups and how these images can be influenced by education: '[...] the image [of the city] is not solely the result of external characteristics but is a product of the observer as well. Therefore it would be possible to improve image quality by education'. Lynch's (1960) framing hints at an interconnection between contemporary city planning and participation processes with methods of architectural education.

Kevin Lynch (1960) started his research interviews with the drawing of a map. Subjective representational drawings of urban environments were crucial to make mental images visible and comparable. The question of how mental maps are in any way similar to physical maps remains unresolved
(Seifert, 2011: p. 56), but the map as a communication tool for urban development should be investigated further. Taking a closer look at Kevin Lynch's (1960) methods of communicating with citizens concerning their image of the city, a method mix of interviews and hand-drawn maps which was used to ask inhabitants and passers-by about their image of the city can be extracted. Before and after the interviews 'trained observers' systematically visited and analysed the area and also produced maps of the area. The individual interviews were interpreted and summarised in a 'probable composite image' (Lynch, 1960: p. 144) by the researchers. Finally, Lynch (1960) juxtaposed nonexperts' and experts' views of the city image to show how they coincide with regard to legibility and problem zones of the city. The legibility of the city image according to Lynch (1960) is based on the concept of the environmental image in urban structure. He related this image to the cultural meaning to be found in 'names and memories, distinctive forms, and holy places' and on 'purposeful mobility' (Lynch, 1960: p. 124).

Kevin Lynch's (1960) method of asking a small sample of non-experts to produce a universal cartographic cognitive map was criticised by cognitive scientists, but he is nonetheless seen as a pioneer for having introduced the consideration of the user perspective in the professional urban planning process (Seifert, 2011: p. 62). The question is: what is lost when the graphic language of the users is adapted to the professional language of the experts, and how could the experts' language learn from the users' language? Here a central point in architectural education is touched on: which language is spoken and to whom is this language accessible? Instead of focusing 
on the legibility of the city this study wants to take a closer look at the 'speak-ability' of the city users, the ability to express their everyday socio-spatial experience.

To discuss urban spaces and atmospheres spatial imagination is needed. The development of spatial imagination in sociospatial science is described as a learning process on the basis of acting in Raumsoziologie (Sociology of Space) by Martina Löw (2001). According to Löw (2001), spatial imagination is an internalised attitude 'die räumliche Vorstellung [ist] eine verinnerlichte Handlung' (Löw, 2001: p. 76) targeted at objects. Urban and educational spatial sequences are superimposed with social and institutional framings. Raising awareness for the perception of space is therefore a key factor in questioning and appropriating concepts of space. The importance of social and cultural impact and the perception of space by all senses are mostly underrated in this context (Löw, 2001). Topological orientation and situational relations are usually not supported in educational contexts; instead traditional Euclidian thinking and concepts of consistent space prevail.

The influence of the school surroundings on the urban knowledge of young citizens has been discussed in recent studies (Coelen et al., 2015). The focus of this investigation is the question of how to communicate with young adults in educational settings with reference to the spatial and atmospheric qualities of their environment. In a case study presented here, the knowledge - and also ignorance - of heterogeneous groups of pupils of their school environment are extracted with the help of individually and collectively drawn thematic maps. Due to the social and cultural diversity of the reference group different environmental images are expected.

The goal of this research is to use strategies of critical cartography (Bhagat et al., 2008) to develop a set of didactic mapping tools. The production of maps in the case study: Atlas of Invisible Spaces methodically focuses on explorative and artistic mapping strategies (Casey, 2006), following the idea that selfauthored maps raise the awareness for the environmental image. This project traces how the discussion of urban phenomena with teenagers supports the articulation of their needs and enables emancipatory potentials for their appropriation of urban space. The school and its environment are finally seen as a network of actors, which is constantly learning through every mapping process. The case study produces a collection of maps to visualise relations between these main actors: young adults, the school and the urban environment.

\section{How can maps contribute to architectural education?}

As he patiently laboured over his mappa mundi for those years, he began to recognize the power of invisible events to change the course of history. What he failed to mention, however, yet it continues to permeate his text to this day, was the idea of an invisible geography affecting the way we think about place. (Cowan, 2007: p. 151)

Today, city images are seen as constructions, which are generated by the users - how can planners access this inner image? In the research project Stadtsurfer, Quartierfans \& Co the team of 'Studio Urbane Landschaften' establishes a setting of interviews in combination with topological models to describe the city constructions of adolescents (von Seggern et al., 2009). This study focuses on the environmental image of the whole city. Nevertheless, the importance of the immediate school environment should not be underestimated. In her dissertation Atmosphäre als partizipative Entwurfsstrategie (Hofmann, 2013) Susanne Hofmann describes atmospheric models as valuable tools to involve users in the design process. Both examples illustrate that models have already been established as low-threshold communication tools between users and planners to talk about spatial relations and atmospheres.

Compared with models maps require more abstraction, so why does this study focus on maps to discuss environmental images? In participatory processes amateur models often focus on objects. They can be the place for a narrative but do not contain the narrative itself. Maps can tell complex stories as they constitute spatial knowledge in a different way. They allow for different scales in one image and encourage the use of images, signs and text on the same level. According to Andrea Sick (2003), maps construct fictions in a field between art and science; they create a landscape of knowledge or 'Wissenslandschaft'. Following this argument, this project explores the potential of maps to show the subjective landscape of urban knowledge of young adults.

In his essay Subjektives Kartographieren Egbert Daum (2011) describes subjective cartography as a socio-spatial practice, which results in a way of making a home Heimatmachen [s] for the urban youth. Subjective maps could thus make transparent how the city image of young adults is constructed. A juxtaposition of authorship in historic maps and contemporary critical maps leads to the assumption that the emancipatory potential of non-standard maps could encourage young adults to write their individual city images themselves.

In the discussed case study, cartographic drawings of a familiar area initiated a dialogue between experts and non-experts. Continuous conversations through drawings led to further maps and encouraged pupils to speak for themselves and exchange their knowledge among themselves. The dynamic process of mapping in a collective made everyday knowledge visible and valuable to all members of the group. The resulting maps were compiled in an atlas-like archive combining the 
representations of real and imaginary city images, individual perceptions and collective learning processes, creating a framework for translating and transmitting the collective city imagery to a public audience.

\section{Case study: Atlas of Invisible Spaces}

In the development of the image, education in seeing will be quite as important as the reshaping of what is seen.

(Lynch, 1960: p. 120)

An image of the city is not only constructed by the existing visible objects but also by how they are perceived depending on what is needed for daily life. Local consciousness is intensively developed in adolescence, a period where young people spend a large amount of time at school and in its environment. Therefore, this project focuses on young adults aged 14-17 years whose view of the city is shaped by routines. Their routines are dependent on their experiences, diverse family and cultural backgrounds; and they have recently started to develop their own city image.

To investigate the spatial image young adults have of their school environment and how this knowledge can be improved, the case study design focuses on one school as a common location. For this research set-up, a prototypical Viennese school in a traditional peripheral district in Vienna with a diverse cultural and social mix of population was chosen. The 15th district 'Rudolfsheim-Fünfhaus' in Vienna has the highest percentage of inhabitants of non-Austrian origin $(52.1 \%)$ and the lowest average income and rent (according to the Department of Statistics of the city of Vienna in January 2016, see: Stadt Wien MA17 (2016) and Stadt Wien MA23 (2016). Settled with villages up to the late eighteenth century, the urban structure of Rudolfsheim-Fünfhaus was mainly built up in a period of massive industrial growth and city development in the late ninteenth century, the so-called Gründerzeit. The area is currently undergoing local transformation; local initiatives of artists and creative businesses have boomed recently (Kogelnik, 2016).

The public school BRgORG Henriettenplatz is a characteristic building of the 'Gründerzeit' period with a socially diverse school community. Starting with an almost microscopic framing in the direct neighbourhood within $250 \mathrm{~m}$ (about 15 min walking distance) around the school the area of investigation would be expandable, depending on the perspective of the participants and the connections the project would possibly establish - instead of being framed by structural patterns as seen from above. In size the Henriettenplatz neighbourhood can be compared with the Beacon Hill neighbourhood analysed in Kevin Lynch (1960: p. 160) The Image of the city (Figure 1). Next to the geographic territory, the school, its teachers and students, its rules and its environment in this

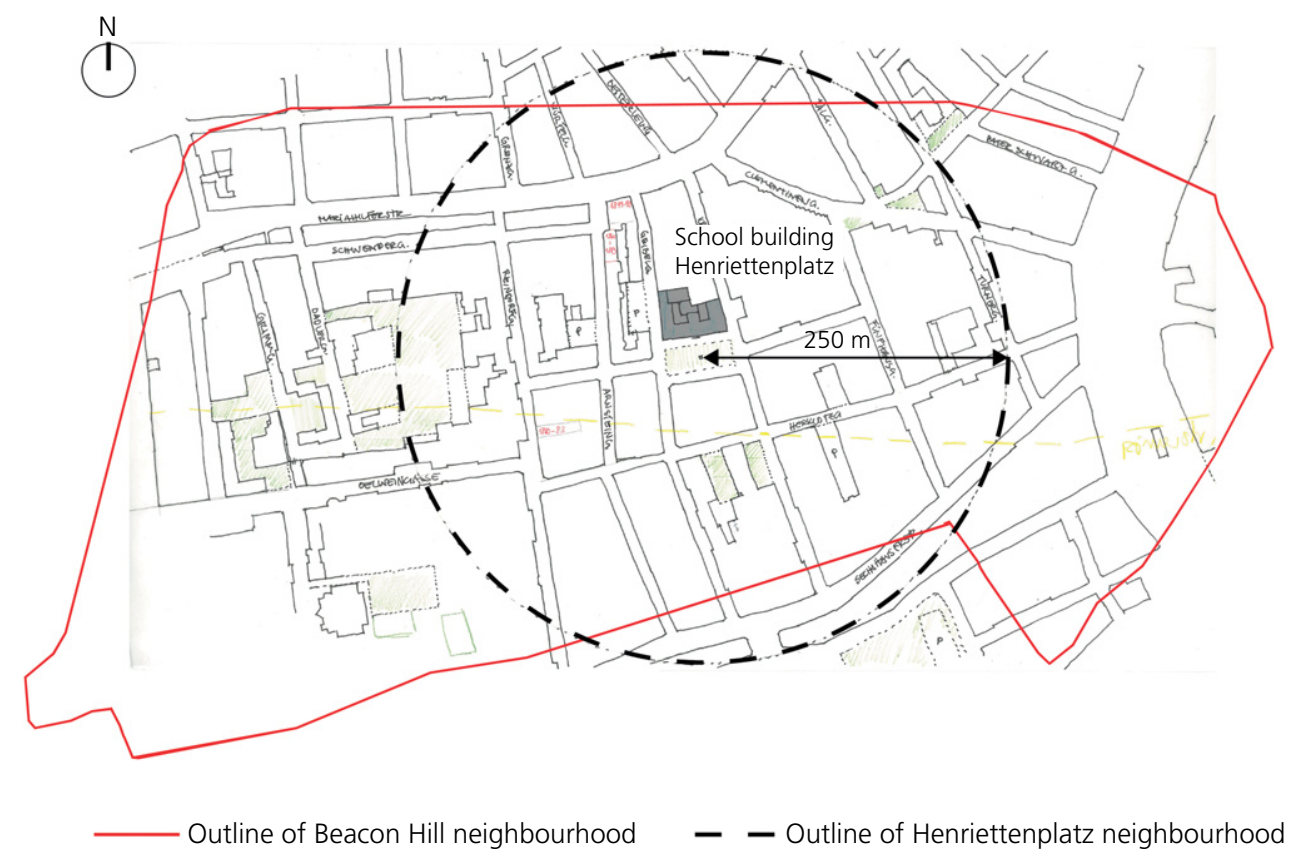

Figure 1. Site of case study in Rudolfsheim-Fünfhaus, district in the suburb of Vienna. Area of the study started in the circle around the school and extended during the project. Total area is similar in size to Beacon Hill neighbourhood investigated by Kevin Lynch (1960) 
project are seen as a 'laboratoire' in the sense of Bruno Latour (Belliger and Krieger, 2006), since they represent another kind of territory. The process of mapping this social network of actors will influence all elements of the territory and the map itself.

To address pupils in their regular educational settings, the authors' research questions for the case study were adapted to match the framework of a school year. The narrative of an expedition into the school environment as an unknown territory was explored in several workshops with different pupils producing thematic maps, three of which are presented here.

\section{Atlas of Invisible Spaces - World Map}

In the first setting two researchers and nine university students from art education studies worked with a group of 20 , 15-16-year old pupils in a fine arts class on a weekly basis between November 2014 and January 2015. After a short introduction to mapping the first exercise for the pupils was to draw a spontaneous map of their daily route to school. The simple sketch map should help a fictive person to find the route to school focusing on landmarks to help orientation and navigation. The maps reflected the cognitive image of the personal way-finding strategies of each author. Comparing these products of momentary imagination made visible the diverse or similar perception of the space constituting elements. There was no judgement of wrong or right as all maps led to the same place, whether they were using Euclidian or topological references, or whether they were drawn in a skilled or simple way. The maps were exhibited in the classroom and the personal routines became a public issue. Through an evaluation of the maps the authors found out that only one-third of the group lived near the school, whereas the majority had to travel quite far from other districts of Vienna.

The next task was to create thematic maps of the school environment. After an excursion to the field, each group established their own approach. Assisted by the students, theme maps were created on themes such as 'favourite places', 'free spaces' and 'non-places'. One group decided to create logos for places of daily importance such as public transport stops, dangerous road crossings, meeting points, places for food and even places they could not relate to, like local hipster shops. Another group concentrated on empty spaces such as parking spots, parks and courtyards. Yet another topic that emerged were uncanny and unpopular spaces, such as a mysterious house and the scene of a witnessed crime - some real, some fictitious. One group documented findings from an expedition where they had arbitrarily followed the passers-by. Once they had started to produce the thematic map each group sent a delegate to construct a map large enough to contain the thematic findings of all groups. This 'World Map' (about $240 \mathrm{~cm} \times 340 \mathrm{~cm}$ ) was drawn jointly without relying on any geographical reference, the streets and spaces evolved through discussion (Figure 2). In a final session all thematic contributions were inserted into the common map. The session concluded with the so-called 'knowledge conference': the pupils prepared an exhibition of their maps and a mini workshop to present the results to younger pupils in an interactive format. In a final discussion, all participants were asked for a comment or reflection on the mapping process.

During the workshop some pupils had asked: 'Why do you ask us? There's nothing special here'. Most of them had never talked about their way to school in such detail nor taken alternative routes. In the final group discussion after having presented the results to younger kids some still doubted that their everyday knowledge about their environment had any relevance whereas most pupils gave positive feedback and told us that they had appreciated the impulse.

\section{Atlas of Invisible Spaces - Multilingual Map}

The next workshop stretched over a period of 6 weeks with another group of some 20,14-15-year old pupils in German class and Art class. In co-operation with the teachers, it was decided to use methods of linguistic landscaping (Multilingual Graz, 2015) to connect the mapping approach to regular teaching contents. In the first session, historic maps were used to demonstrate that every person could be an author of a valid

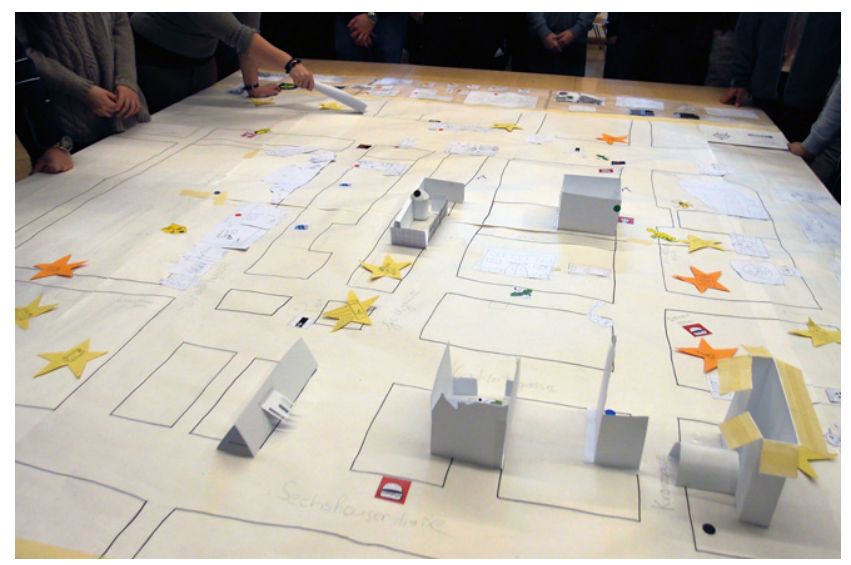

Figure 2. The World Map shows findings concerning free spaces (built as models), logos for special places (square stickers), uncanny places (yellow drawings) and observations during a 'derive' (white sketches). Yellow and stars mark places for change defined in the workshop with younger pupils. Photograph: Antje Lehn. Figures may not be fully interpretable in greyscale. Please consult the colour online version if necessary. A full-color version of this figure can be found on the ICE Virtual Library (www. icevirtuallibrary.com) 


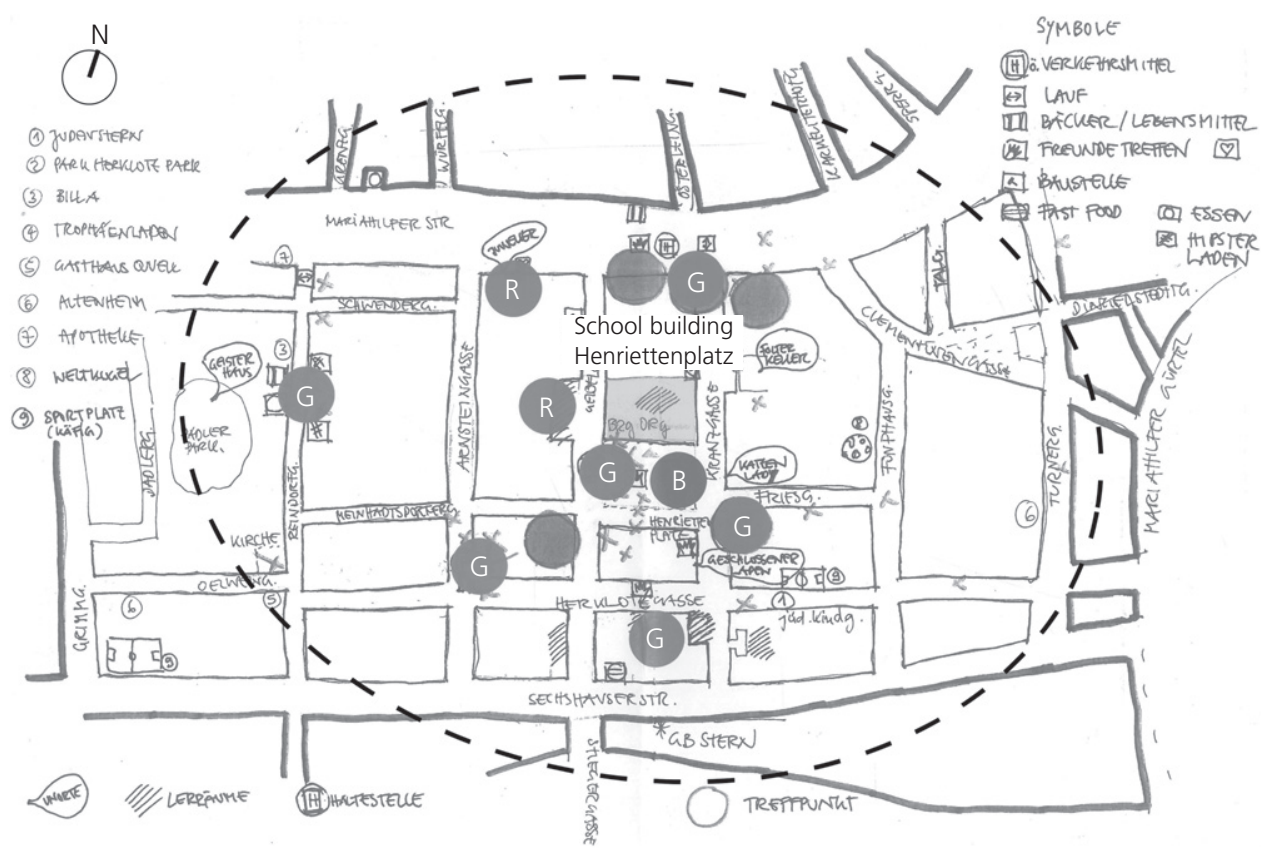

Figure 3. First meta-map produced by the author summarises all findings of the first Atlas section based on the World Map. Scale and proportion are not continuous, dashed line indicates research area. Grey and green (G) dots indicate important meeting places, red (R) dots indicate problematic places, blue (B) dot indicates sports facility in front of the school. Figures may not be fully interpretable in greyscale. Please consult the colour online version if necessary. A full-color version of this figure can be found on the ICE Virtual Library (www.icevirtuallibrary.com)

map of their own territory, afterwards pupils were asked to sketch their daily school routes using drawings of landmarks instead of words for orientation.

Before exploring the neighbourhood actively the topic of multilingualism had been discussed in class. An individual language portrait reflecting the students' biographies mapped 15 languages in the group of about 20 pupils. To survey multilingual places in the school surroundings, pupils were asked to take photographs and to make interviews in the area. They documented the country of origin, length of residency, first language and languages spoken of the interview partners and found a variety of migrant biographies. The collective map was put together on the basis of a meta-map (drawn by the author) summarising all findings produced during the 'Word Map' process (Figure 3). The final product was a collaged 'Multilingual Map' $(135 \mathrm{~cm} \times 120 \mathrm{~cm})$ visualising the linguistic landscape of the school environment (Figure 4). The combination of retraced photographs and transcribed interviews showed polylingual identities behind the facades of 12 local shops and some other places. Finally, the class was asked to draw illustrative symbols to produce a map key. By assembling the map themselves and by defining the rules about how to read it, pupils gave their own findings a framework that

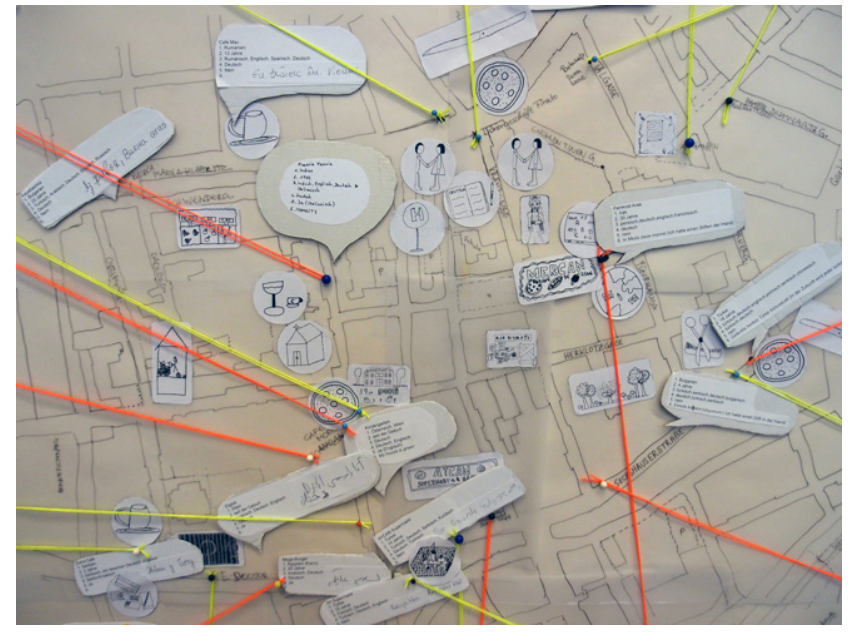

Figure 4. Multilingual Map collage. Speech bubbles contain short interviews related to the place of interview. Connections to city images on the periphery of the map are indicated by coloured strings. Round stickers reference to map key. Photograph: Antje Lehn. Figures may not be fully interpretable in greyscale. Please consult the colour online version if necessary. A full-color version of this figure can be found on the ICE Virtual Library (www. icevirtuallibrary.com) 
Urban Design and Planning

Volume 171 Issue DP1
Atlas of Invisible Spaces: mapping in school environments

Lehn resembled normative maps and therefore established some kind of authority.

To reflect the process, the presentation of the collective map was combined with a fishbowl discussion focusing on the question: Why draw maps? The discussion with guests from the fields of (art-)history, ethnography and pedagogy has shown that by learning how to draw a map of their own, the participants were empowered to speak about their individual view of the city. The guests encouraged the students to become aware of how much they know and to trust their own perception and expertise of their surroundings: 'In this map you can find yourselves - the people who have produced it'.

\section{Atlas of Invisible Spaces - Atlas of Urban Actors}

In the last part of the project all maps produced during the year were collected and made visible in an installation in public space, which also provided the framework for a collective mapping event. Three weeks before the event the author prepared two mini workshops with 12 pupils from the same group as in the previous project. A history workshop in co-operation with the local library and the district museum questioned how city images are influenced by memories and atmospheric framing. A workshop on multilingualism produced a diagram of migration routes and the idea of a translation service for the event.

In co-operation with a group of artists Eintagsmuseum a collaborative setting was developed: a public sculpture with a large mapping table, a meta-map of the school environment summarising the findings of all previous workshops, a prepared environment of worksheets, stickers and pens enabling everybody to leave traces in the map. Pupils and teachers of the school, neighbours, restaurant owners, office workers, local businesses, private initiatives and passers-by were invited to participate in the so-called 'Co-Laboratory'. The large makeshift wooden construction drew attention to the public audience (Figure 5); an 'Audio-Expedition' and a 'Language Workshop' offered interactive formats in addition to presentations of the processes behind the 'World Map' and 'Multilingual Map'. One group had compiled all the places the classmates had lived in before joining the school. The resulting 'Diagram of Migration' (Figure 6) produced the effect that the longest route looked the most interesting. As a matter of fact, only one student out of 12 originated in Austria. Several local actors like the graphic design office, the refugee café, the neighbourhood initiative, the old couple and lots of kids visited the event and left their traces (Figure 7). As the wooden structure became a temporary three-dimensional cluster of everyday knowledge, the Atlas of Invisible Spaces revealed its potential as a tool for public negotiation of meaning.

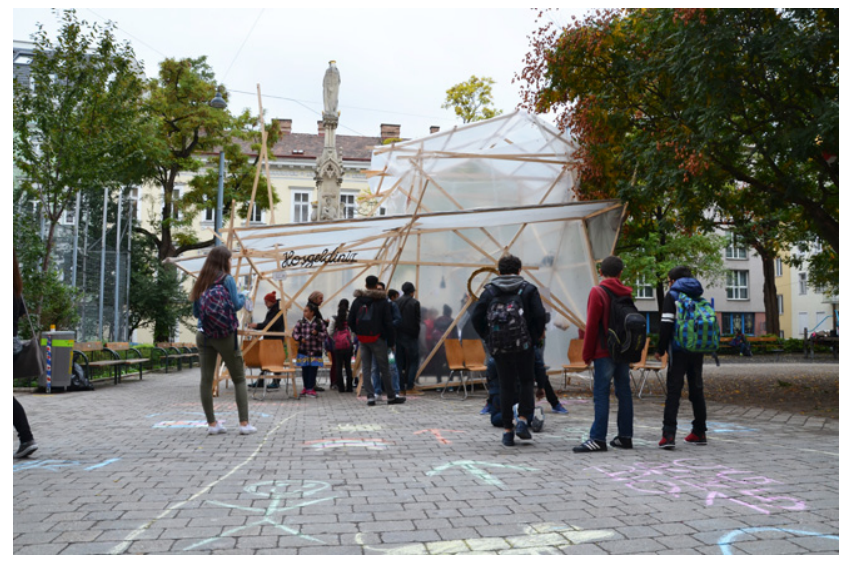

Figure 5. Installation view of Atlas of Urban Actors on public square (Henriettenplatz) in front of the school. The makeshift construction attracted curious visitors from the school and the neighbourhood. Photograph: Johanna Reiner

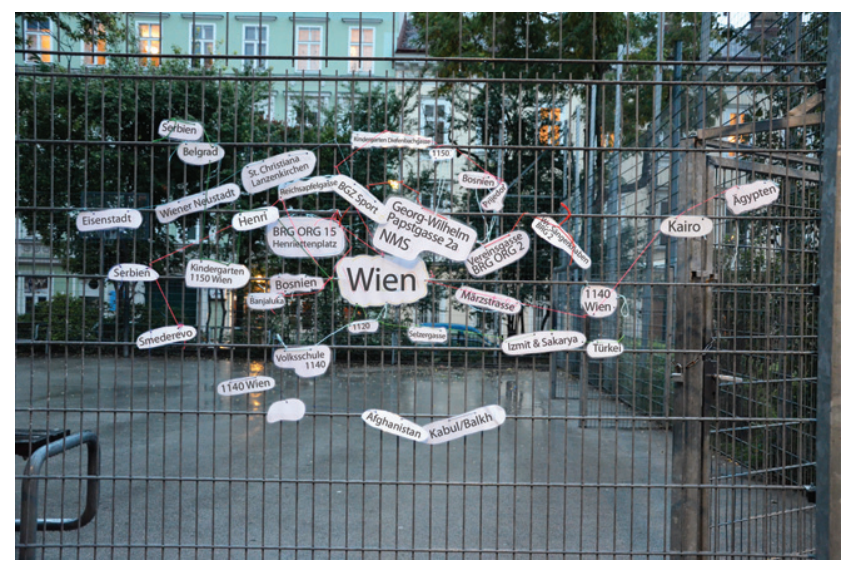

Figure 6. Diagram of migration developed in a workshop. Places of migration are connected with colour-coded string. To show the individual route from place to place, school to school until arriving at Henriettenplatz, Vienna. Photograph: Johanna Reiner

\section{Findings: education of seeing - reshaping what is seen}

The transdisciplinary approach of connecting town and city planning with pedagogics and architectural education is based on the author's interest in the relation between the school and its surroundings. The main contribution of this research lies in the exploration of cartography as a tool for communication between experts and non-experts. The basic idea was derived from historic portolan maps of the Renaissance in which map knowledge was created through the collaboration between travellers (founded on experience) and geographers (founded on science) - significantly artists 


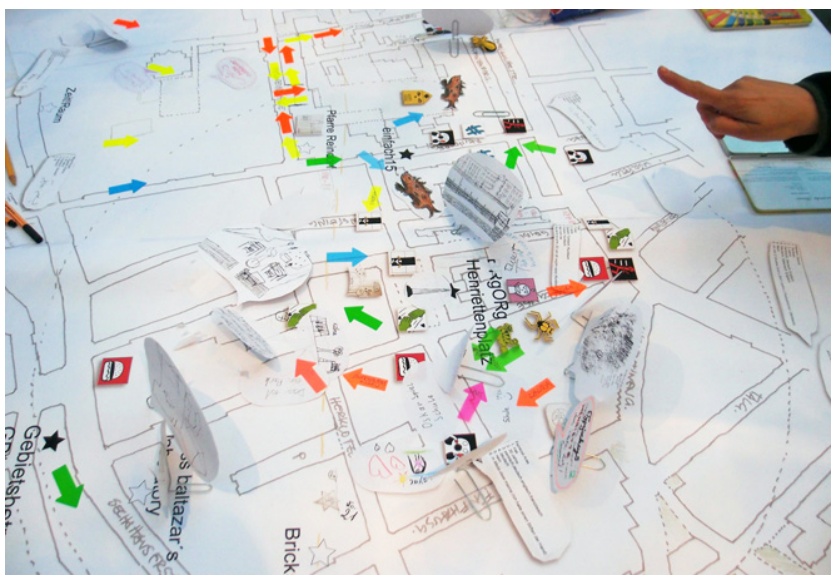

Figure 7. Second MetaMap produced by the author after stickers and notes were added during collective mapping workshop at Atlas of Urban Actors event. Arrows in the foreground indicate where participants live, arrows in the background were applied by smaller kids without rules. Vienna. Photograph: Antje Lehn

participated in both realms and together they produced valuable images of the environment.

The initial exercise to draw the map of the way to school was repeated with every group and produced formally comparable drawings. As the majority of the kids lived quite far from the school the maps were dominated by interchanges and stops of public transport. Further pupils frequently drew trees or parks, sports fields, supermarkets and fast food shops, less frequently churches or other buildings as indicators of place. The drawings accumulated statistical knowledge about where the pupils lived and which routes were used but its main purpose was to trigger communication on each other's routes as they became visible.

The 'World Map' made marginal spaces and individual perception of atmospheric qualities in the school environment visible to the group. In a written feedback interview done in dialogue with the author before the 'Knowledge Conference' pupils were asked 'What is missing or what could be improved in your map?' Some considered their own hand-drawn maps as inaccurate or unfinished: 'There could be more precision, information, structure'; others were satisfied with the result and claimed that 'Nothing is missing'. Another feedback question aimed at what had been learned in the process, here some pupils remarked that they had learned to look closer and improved their knowledge about the district, whereas others claimed that they had learned nothing new or would prefer to explore their environment themselves. The thematic map exercise had shown that visual information, imagination, memories, emotional knowledge and other perceptions of each group member could tell a story if displayed strategically on the surface of a map. For the pupils, the result was convincing as the map became a tool to present the topic to their fellows: 'For me it was interesting to see how to make a map'.

The 'Multilingual Map' showed diverse linguistic cultures in the neighbourhood. The teenagers stated that they had gained new perspectives of their familiar environment by exploring it with curiosity, stepping across borders and speaking with strangers: 'I liked when we were drawing, it was interesting. The interviews were cool, we could hear from others how they lived'. About a year later this map was included in an exhibition called Die Zukunft der Stadt (The Urban Future) in the Technical Museum, Vienna and the pupils were invited to the museum. The public interest of an institution provided positive feedback to the participants and proved that they had created a relevant contribution to the topic.

Before the public 'Co-Laboratory' Atlas urbaner Akteure (Map of Urban Actors) all formats were revised to extract which methods and topics had worked best in the different exercises. To create a transferable set of didactic mapping tools, the teenagers' reactions to the different topics were evaluated. The maps marking the atmospheres of popular/unpopular places, and those visualising memories/history were most successful - as they were relating to the everyday life of the teenagers. Further, the maps in conjunction of language and origin were stimulating as they were connected to questions of identity and self-esteem. In a next step, these mapping themes will have to be refined and tested again.

During the period of the case study two participation processes were implemented in the area, one dealt with the transformation of a former parking lot to a park, while the other proposed the revival of a local market. The latter process was especially criticised as local politicians had ignored the existing communities built by activists. The case study discussed in this paper tested low-threshold mapping strategies to bring everyday knowledge to the attention of local actors and planners. As a conclusion, methods of collective narrative maps could be applied to create more sustainable processes of Wunschproduktion (production of desires) for local city planning issues.

As the project's characteristic is mainly explorative and experimental not all of its effects could be scientifically documented. The school and its environment were looked at as a network of actors, which was affected by the mapping processes - just like the 'Collaborative Lab' in front of the school initiated another level of communication between the school and its surroundings. Setting up a collective project in an open process was extremely challenging within the social fabric of the school as it also included the implementation of untypical structures and 
methods. As maps tolerate verbal and non-verbal information, different scales and even blurriness in one image, the map format allowed to contribute diverse expressions, the normative standard was not given but had to be negotiated by the group. Most pupils still tried to produce perfect drawings in order to succeed in the context of their art class and therefore were confused by the demand of frequent revision of the map drawings. To challenge this attitude, subversive methods such as 'unlearning' to draw were introduced. Effects of these kinds of pedagogical interventions could be further explored in accompanying research.

\section{Conclusion}

Accessible participation in town and city planning is usually seen as a problem of translating expert knowledge to nonexperts, complex things have to become simple. By means of an explorative study, the project Atlas of Invisible Spaces investigated in which way artistic mapping methods could be useful to establish a process-orientated visual language for exchanging urban perception. Raising the awareness for city structures among adolescents and testing experimental notational methods were the key achievements. Further potential of the collective mapping processes could be the collection of data on local urban atmospheres and communities.

Using a historic map like the fifteenth century Mappa Mundi of Fra Mauro as role model for communication processes proved to be a good guidance - it helped to find methods of mapping as a collective. Pupils preferred topics such as memories/history, language/identity and places/atmospheres as they related to everyday culture, again the reflection and discussion was more important than the resulting map. The discussion of urban culture in school environments has a potential to cross disciplinary borders and challenge stereotypes in the subjects such as geography, history, art and language - here the collaboration with the teachers needs to be prepared more thoroughly.

The balance between graphical compilation and non-linear generation of content should be explored further, as the placing and replacing of graphical elements showed a potential for methods of non-verbal debate and the open processes allowed to insert topics along the way. Even though the rather explorative 'World Map' triggered interesting processes, the 'Multilingual Map' showed a better balance between process and result. Assembling interview texts with photographs and a city plan in a collage (Figure 4) allowed every group member to contribute, the process remained visible and the resulting map was legible and attractive. The element of presentation of the newly gained knowledge to others (pupils, teachers, public) is crucial as it strengthened the self-esteem of the group as they could experience themselves in the role of experts.
The focus on teenagers and their school environment in the urban periphery framed a prototypical set-up, which could be transferred to other educational environments in Vienna. The size of the research area proved to be small enough to be explored in the given time frames, but still big enough to contain a range of atmospheres, unknown places and infrastructures. In the future, it could be useful to extend the body of participating researchers to other fields in order to ask the participants about their position towards the school environment and comparing their environmental image before and after the project. In particular, it would be interesting to team up with social geographers for qualitative interviews in a similar laboratory setting.

\section{Acknowledgements}

The author acknowledges Professor Angelika Schnell, Platform History Theory Criticism, Institute for Art and Architecture, Academy of Fine Arts Vienna and Dr Oliver Friedrich for the scientific support for this paper.

\section{Case study Atlas of Invisible Spaces}

In the section 'World Map,' I collaborated with Dr Anna Pritz (as co-researcher) and students of the Institute for Education in the Arts, Academy of Fine Arts Vienna: Isabell Girod, Judith Auer, Anna Winkler, Doris Stein, Caro Estrada Steiger, Kathi Puffer, Eva Eisner, Lydia Lechner, Claudia Liedtke. In the sections 'Multilingual Map' and 'Atlas of Urban Actors,' I cooperated with Johanna Reiner as collaborating artist. Further team members: Frank Hagen, Johannes Hofmann, Günay Özayli, Elke Rauth.

The case study was based on the contributions by 50 pupils and accompanied by the teachers Irene Bittner, Eva Eichmair, Caro Estrada Steiger from BRgORg Henriettenplatz.

Guests: Barbara Feller, Liz Hirn and Elisabeth Sattler.

Case study supported by Akademie geht in die Schule (http://akademie-in-schulen.akbild.ac.at) a project at the Academy of fine Arts Vienna within the framework of Hochschulraumstrukturmittel.

\section{REFERENCES}

Barthes R (1982/1992) The Empire of Signs. Hill and Wang, The Noonday Press, New York, NY, USA.

Belliger A and Krieger DJ (eds) (2006) ANThology, Ein einführendes Handbuch zur Akteur-Netzwerk-Theorie. transcript Verlag, Bielefeld, Germany (in German).

Bhagat A, Mogel L and Paglen T (2008) An Atlas of Radical Cartography. Journal of Aesthetics and Protest Press, Los Angeles, CA, USA.

Casey E (2006) Ortsbeschreibungen, Landschaftsmalerei und Kartographie. Fink Verlag, München, Germany (in German). 
Coelen T, Heinrich AJ and Million A (eds) (2015) Stadtbaustein Bildung. Springer Fachmedien, Wiesbaden, Germany (in German).

Cowan J (2007) A Mapmaker's Dream, The Meditations of Fra Mauro, Cartographer to the Court of Venice. Shambhala, Boston, MA, USA.

Daum E (2011) Subjektives Kartographieren. sozialraum.de 1/2011. socialnet $\mathrm{GmbH}$, Bonn, Germany. See http://www.sozialraum. de/subjektives-kartographieren.php (accessed 05/01/2014).

Hofman S (2013) Atmosphäre als partizipative Entwurfsstrategie. Dissertation, TU, Berlin, Germany. See http://opus4.kobv.de/opus4tuberlin/frontdoor/index/index/docId/1049 (accessed 16/01/2014)

Kogelnik L (2016) Reindorfgasse: Vom Schmuddeleck zur Kreativszene. derstandardat 13.03.2015. STANDARD Verlag, Wien, Austria. See http://derstandardat/2000012854469/Reindorfgasse-VomSchmuddeleck-zur-Kreativszene (accessed 01/02/2016).

Löw M (2001) Raumsoziologie. Suhrkamp, Frankfurt am Main, Germany (in German).
Lynch K (1960) The Image of the City. The M.I.T. Press, Cambridge, MA, USA.

Multilingual Graz (2015) http://multilingual.uni-graz.at/projekte.html (accessed 18/05/2015).

Seifert J (2011) Stadtbild, Wahrnehmung, Design: Kevin Lynch revisited. Birkhäuser, Basel, Switzerland (in German).

Sick A (2003) Kartenmuster. Bilder und Wissenschaft in der Kartografie. Dissertation, Fachbereich Sprachwissenschaften der Universität

Hamburg, Hamburg, Germany. See http://ediss.sub.uni-hamburg. de/volltexte/2004/1179/pdf/dissertation.pdf (accessed 18/11/2014).

Stadt Wien MA17 (2016) https://www.wien.gv.at/menschen/integration/ grundlagen/daten.html (accessed 01/02/2016).

Stadt Wien MA23 (2016) https://www.wien.gv.at/statistik/arbeitsmarkt/ tabellen/einkommen-gesamt-bez.html (accessed 01/02/2016).

von Seggern H, Schmidt A, von Detten B et al. (2009) Stadtsurfer, Quartierfans \& Co - Stadtkonstruktion Jugendlicher und das Netz urbaner öffentlicher Räume (Stiftung W (ed.). Jovis, Berlin, Germany (in German).

\section{How can you contribute?}

To discuss this paper, please email up to 500 words to the editor at journals@ice.org.uk. Your contribution will be forwarded to the author(s) for a reply and, if considered appropriate by the editorial board, it will be published as discussion in a future issue of the journal.

Proceedings journals rely entirely on contributions from the civil engineering profession (and allied disciplines). Information about how to submit your paper online is available at www.icevirtuallibrary.com/page/authors, where you will also find detailed author guidelines. 